\title{
POSTINDUSTRIAL ELITE AND NON-ELITE INSECURITIES
}

\author{
JOHN HIGLEY ${ }^{l}$
}

\begin{abstract}
Two growing conflicts, peculiar to postindustrial societies, challenge the ability of elites to keep postindustrial politics manageable. These are (1) a conflict between elites and those non-elites who remain reasonably well integrated in the productive and social orders of postindustrial societies but who feel themselves vulnerable to elite personnel decisions they regard as arbitrary and uninformed - 'insiders'; (2) a conflict between insiders and the many persons in postindustrial societies who are more or less unemployable for objective or subjective reasons and located in strictly marginal or wholly superfluous work and dependency statuses - 'outsiders'. Both conflicts impede the managerial roles of elites and raise questions about how postindustrial societies can be sustained without suffering organizational paralysis and the socioeconomic retrogression that would accompany it.
\end{abstract}

KEYWORDS elites, bureaucratic and service personnel, leisured youth, disadvantaged population categories, social control

A society becomes postindustrial when 40 percent of its workforce is employed in bureaucratic and service work, a proportion that increases quite rapidly to 70-75, even 80 percent (cf. Bell 1999: xv). By the 1950s the composition of workforces in the United States, Great Britain, the Netherlands, Denmark, Sweden, and Canada had reached the 40 percent threshold to postindustrial conditions, and during the succeeding two or three decades virtually all other Western countries, plus Japan, crossed it. Quite unforeseen by nearly all observers at the time, non-elites in the first postindustrial societies began to divide into two loose interest and attitude camps during the 1960s and 1970s. The camps' boundaries were not contiguous with those of the classes and strata that derived from the agricultural, manual industrial and non-

1 John Higley is professor at the University of Texas at Austin; e-mail: jhigley@austin.utexas. edu; University of Texas at Austin, Texas, USA 78712. 
manual workforce components so prominent during historical socioeconomic development. One camp, which it is convenient to label 'insiders', consists of all the persons more or less securely and satisfactorily employed in the workforces of postindustrial countries, plus the many persons in comfortable and honorific statuses as dependents of these employees. More specifically, the insider camp contains: (1) the bulk of non-manual bureaucratic and service workers, especially those holding relatively interesting and responsible jobs as middle- and upper-level managers, professionals and their assistants, as well as specialists in many services; (2) reasonably prosperous farmers and artisans; (3) skilled manual industrial workers holding decently paid jobs that are usually protected by strong trade unions; (4) persons in more or less honorific statuses such as better-off retired persons and persons directly dependent on the foregoing categories of workers, such as spouses, children, offspring in educational institutions, and elderly parents.

The other camp, 'outsiders', contains two non-elite segments with distinctly different social experiences, and this difference tends to prevent them from acting as a single and self-conscious political force. One segment encompasses people in conditions of poverty who are largely outside the dominant cultures of postindustrial societies, together with an indeterminate number of people suffering severe personal handicaps of a physical or emotional kind. Most of these people are without marketable work skills or, at least, without the attitudes necessary for regular employment in organizationally complex and technologically sophisticated work environments. Employers find it uneconomic to pay many of these persons a living wage for the relatively few kinds of work they may be able and willing to undertake, and there is, in any case, no pressing need for such work.

The second segment of outsiders encompasses many persons who experience what are essentially leisure-class upbringings. Although there is probably a tendency in any urban setting to treat children as luxury items to be pampered and displayed, a steady decline in available jobs for teenagers in postindustrial cities reinforces this urban tendency. Parental incomes are high enough so that idleness and boredom do not become serious problems for these young people until their later teenage years. During their childhoods and much of their adolescence they engage in pleasurable activities provided by parents, schools, and a wide variety of sport, hobby, and other organizations. Although many leisured young people manage to find part-time employment for short periods, the income they earn is used mainly to purchase fashionable goods, their own automobiles, and entertainments. Typically, this part-time employment is not seriously timeconsuming, nor is it necessary in any urgent way. To a considerable degree, it is a distraction from idleness and boredom. 
Most of the activities in which these leisured youth engage have no serious ulterior purpose, except possibly an educational one. Their activities cannot be related plausibly to the needs of other people or to society as a whole. Engaging in them does not involve accommodating seriously inconvenient wishes of adults or practicing much self-discipline by, for example, deferring immediate gratifications. Because their leisured circumstances are generally comfortable and entertaining, comparatively few leisured young people develop substantial personal ambitions. Unlike the great bulk of young people in all previous societies, they have no strong urge to reach adulthood. Just as it was always difficult historically to instill provident and responsible behavior among the indulged offspring of aristocrats and other wealthy families, so it is difficult to teach prudent standards of adult behavior to leisured young people in postindustrial societies.

It is ironic that the pleasant and more or less absorbing activities of these young people create problems of adjustment later in life, but there is a good deal of evidence that this is so. One reason is that the affluence enjoyed by most leisured young people proves to be quite limited. It depends almost entirely on parents' incomes. Although those incomes are far above historical levels, they are nevertheless tied to the holding of specific occupational positions. Relatively few parents have extensive property holdings or other accumulated wealth that can be passed on to their offspring. Once the parents retire or die, their offspring have little prospect of leading adult lives that will in any major way be as leisured as the upbringings they have experienced. Accordingly, life's prospects increasingly look fairly grim to many leisured adolescents as they approach and reach adulthood.

Except for the relative few who emerge from their upbringings with exceptional ambition, leisured youth tend to face adult life with resignation, and not a few want to evade its responsibilities to the extent they can. Needless to say, young adults with this outlook are nearly as unemployable as those with outlooks shaped in deprivation and poverty. Just as there is little need for the kind of routine work the latter can perform, so there is little need to employ immature, inexperienced, and unenthusiastic young adults in bureaucratic and service positions. Thus, although their backgrounds and social locations differ dramatically, persons in the two outsider segments have in common an inability or reluctance to participate fully in the workforces, labor markets, and occupational career structures of postindustrial societies. Taken as a single collectivity, then, outsiders consist of: (1) unemployed persons; (2) persons precariously employed in less desirable jobs or in 'make-work' jobs openly created to absorb them into the workforce; (3) persons who manage in one or another way, because of some obvious or at least plausible incapacity, to be 
supported in meager and non-honorific statuses by society or by individual benefactors; and (4) dependents and hangers-on of all these persons.

The proportion of non-elites in postindustrial societies that outsiders comprise appears to increase with the length of time a society has a postindustrial work force configuration. In societies that came somewhat later to post-industrialism - Australia, France, northern Italy, New Zealand, Switzerland, Spain, West Germany - outsiders became conspicuous mainly during the 1980s. But they were quite visible a decade or two before that in the initial postindustrial societies, most especially the United States, Great Britain, and the Netherlands, in all three of which racial features accentuated the distinctiveness of many outsiders. The emergence of insider and outsider camps is a principal consequence of post-industrialism. As was the case with workforce components and the classes and strata based on them in previous stages of socioeconomic development, it is the relations between these nonelite camps and between them and elites that are important sources of social and political conflict in postindustrial societies.

\section{RELATIONS BETWEEN ELITES AND INSIDERS}

Theinterdependentdecision-making thatmostworkin postindustrial societies entails contributes to a greater understanding and acceptance of the necessity for power exercises by socially remote persons than is the case in industrial and pre-industrial societies. This is because the daily work experiences of by far the largest segment of workers - non-manual bureaucratic and service personnel - involve more or less constant and instrumental manipulations of social strangers in extended and impersonal organizational hierarchies and in interactions between service providers and their socially distant clients and customers. With at least one bureaucratic or service worker located in most nuclear families, a 'managerial' orientation that tends to regard power exercises as necessary means for the regular and efficient performance of work tasks pervades the insider camp, and in spite of the different categories of workers and dependents this camp contains (Field - Higley 1980: 26-27). As a result, the dominant culture displays a more sophisticated understanding of organizational imperatives. There is tacit recognition that elites, like less strategically placed power wielders, manipulate the behavior of other persons in order to make large and impersonal bureaucratic and service endeavors possible. Moreover, insiders tend to view these endeavors as essential to the attained level of affluence and productivity, whether the endeavors are humanly satisfying or not. 
But this widespread if tacit understanding of the need for elites does not necessarily lead to an equally widespread acceptance of the roles, statuses, and behaviors of current elites or specific elite persons. Many insiders can generally acknowledge the necessity for organizational hierarchies and for elites to head them up and yet still suppose that the manipulation of personal conduct for organizational ends might be better - that is, more humanely, more wisely - done by persons other than those who currently have elite status. Similarly, many can regard proposals for altering the ways in which elites obtain and exercise power as desirable and plausible: choosing elites more democratically; insisting on shorter elite tenures; requiring that elite decisionmaking be more transparent, and so on. In addition, the recrudescence of populism in all postindustrial societies during recent decades inclines many insiders to entertain reforms that would enable major organizational decisions to be taken by organizational participants themselves. In many universities, notably in Europe, such reforms have been implemented to a considerable extent, as have variants of the German 'co-determination' scheme that pays more than lip service to participatory decision-making in business firms and government agencies. However, most large organizations in postindustrial societies are subject to private property rights or the constitutionally specified rights of superior political authorities, and these limit the extent to which decision-making can be made more participative.

Because of these limits, and because the necessity for organizational hierarchies headed up by elites is at least tacitly acknowledged, the discontent of many insiders with current elite persons and statuses has moved in an oblique direction. This is the widespread demand for procedural safeguards that allow the greatest possible 'input' of interested opinion and sentiment into decision-making processes. In effect, insiders demand that these processes be formalized, even 'judicialized', so that although elites still make final decisions, their actual latitude of choice is slight. Universities are a locus for the formalization of organizational decisionmaking, allowing non-academic staff and students to have inputs that are more or less co-equal with faculty inputs into decisions that are taken ultimately by top administrators, whose hands are tied significantly by the inputs. But because the bureaucratic and hierarchical structures of universities are puny compared with most other organizations, and because these structures are not indispensable to the primary university tasks of teaching and research, the formalization of decisionmaking in universities is mostly just time-consuming and does not greatly affect how their primary tasks are performed.

Where bureaucratic and hierarchical structures are more essential for the performance of primary tasks - in commercial firms, government agencies and many smaller service enterprises - the widespread encouragement of 
committee decision-making accompanied by encounter-group exercises and techniques such as sensitivity training indicate a similar trend to restrict the decision-making latitude of elites. More importantly, in virtually all collective bargaining contexts, between labor and management as well as in relation to white-collar and professional employees, rules and regulations are adopted that severely formalize the hiring, firing, promotion, and task re-assignments of personnel. This is especially pronounced in decisions affecting workers who have seniority or tenure rights, but it extends to employees seeking those rights. The recent skirmish in France about whether employers should be allowed by law to terminate new and young employees before a legally mandated two-year probationary period of work is completed is but one example of the heated conflicts that swirl around these formalizations.

If they continued unchecked, efforts to formalize and even judicialize organizational decision-making, making it more open and subject to pressures by affected personnel, would eventually more or less eliminate elite decisionmaking and, thus, elite statuses. This is a prospect that is wholly peculiar to postindustrial societies. In all earlier societies the elimination or at least severe truncation of elite decision-making in organizational matters was literally impossible because most workforce members were insufficiently sophisticated about complex organizational functioning to be able to bring it about. In addition, the line-up of political forces in such societies guaranteed that experiments in this direction never got much of a trial. The possible exceptions were leveling revolutions in largely agricultural societies that involved full or partial destructions of existing elites. But as the French and Russian revolutions and their aftermaths showed, revolutionary eliminations of elites are brief, they trigger drastic declines in economic productivity and well being, and they are followed by prompt returns to organizational hierarchies headed up by new or restored elites who have more latitude for decision-making then was available to elites before the revolutions.

It is not possible to be so categorical about the situation in postindustrial societies. The work experiences and numerical dominance of non-manual bureaucratic and service personnel provide much greater sophistication about organizational matters, and the trend toward formalizing elite decision-making, by now well advanced, has not as yet resulted in organizational disaster. The interesting question is how far postindustrial societies can proceed in this direction. Are major further steps 'impossible' in the less literal sense that bureaucratic organization would at some point become paralyzed so that resulting chaos would lead to economic retrogression or to an authoritarian restoration of wide elite decision-making latitude? The answer involves several issues in the theoretical understanding of elites. 
Most major organizational decisions, even when they are not explicitly personnel decisions, have important implications for the careers of many organizational members. As regards such decisions, these members are vitally interested parties, and they cannot be expected to show restraint or impartiality in processes leading to the decisions. If anyone can be expected to judge more or less impartially in the interests of the organization (or the society), it is those whose own careers have already been successful enough so that further advancing their personal interests is not a pressing concern. Normally, such successful persons occupy the paramount or 'elite' positions in large organizations (Higley - Burton 2006:5-8). It is conceivable that in oldfashioned bureaucratic and hierarchical structures, where there were virtually no formalized 'inputs' of the kinds organizations in postindustrial societies allow, major organizational decisions affecting the careers and lives of many personnel were made as prudently and responsibly as they ever can be.

The postindustrial trend toward formalization makes it unlikely that decisions generally acceptable to all or most organizational participants can be reached. The rival interests of persons vitally affected by these decisions stand in the way. Formalization makes these rivalries more public, and in so doing it exacerbates emotions and feelings that surround them. Reforms aimed at formalizing and opening up choices between rival interests are most likely to result in postponements, evasions, or compromises aimed at placating all interested parties. Furthermore, although the making of choices is usually necessary because of an organization's limited resources, which choice to make is very often an arbitrary matter except from the selfish standpoint of the person(s) the choice benefits. For an elite decision-maker to make such choices privately, even if he or she simply flips a coin, is quite possibly less harmful in the long run than pretending publicly that a rational, defensible choice has been made impartially after a full airing of rival arguments and claims.

These considerations imply that elites in postindustrial conditions must find ways to preserve the essence of their decision-making power and latitude. They must do this not merely to defend their own interests, but because if they allow themselves to become enmeshed by procedural safeguards and requirements of openness and transparency in making decisions, then intraorganizational conflicts will be enflamed to a point where paralysis in one or another guise will set in. This would gravely impede the material productivity and political orderliness of postindustrial societies. It is important to underscore, however, that this is in no sense an argument for curtailing the functions of representative bodies, political parties, or electoral systems as they now operate in postindustrial societies. As observers of these institutions 
frequently observe, they do not greatly restrict the influence and power of elites (see Borchert 2009; Körösényi 2009). They do, however, ensure that major questions are referred to forums that symbolize the public interest (Engelstad 2009). In addition, they operate to make major choices of political leaders when it is necessary to do so, and they provide peaceful means by which incompetent or unworthy leaders may be removed (Schumpeter 1942; Przeworski 1999).

The next question is whether elites will be able to do this. Is it possible to find ways in which the making of most day-to-day decisions will continue to be mainly in elite hands and yet be generally acceptable to salient insiders? In earlier societies bureaucratic and service personnel (or insiders) were managed by elites because they were willing to trust elite decision-making to serve their own interests. Most fundamentally, this earlier inclination to trust elites rested on the self-confidence that most bureaucratic and service personnel had. Typically, those who complained about decisions or sought to restrain elite decision-making were thought to reveal their own insecurity or weakness, and it was usually quite inexpedient to be perceived in this way. In earlier societies, too, bureaucratic and service positions and statuses were justified in terms of what could plausibly be viewed as 'merit', even if the formal organizational procedures connoted by this term were not always present. Those who did non-manual work were mainly persons who were convinced of their own qualifications for the positions they held or to which they aspired, even in the face of serious competition by others. Although they feared that favoritism might sometimes lead to the advancement of the wrong persons, by and large they counted on their own qualifications to impress superiors with the need to employ them suitably according to organizational needs. In this posture, they had no serious distrust of elite decision-making per se. It was all the easier to take this posture because it was readily apparent that the number of persons qualified and available for responsible organizational positions was quite limited. Only a small proportion of nonelites had opportunities to acquire the verbal skills, personal demeanors, and rudimentary formal educations needed for such positions. Indeed, to be in non-manual employment at all (presuming that one had to work for a living) was a substantial indicator of qualifications that elite decision-makers could not easily disregard.

Obviously, the situation is quite different in postindustrial societies. For most bureaucratic and service positions, especially those in which persons are employed initially, the qualifications needed are not specific or technical. They consist of linguistic and social skills and a broad acquaintance with social structure. Most children and youth who grow up in 'cultivated leisure' 
acquire such skills and social knowledge. Moreover, post-secondary education is readily available to a much larger proportion of non-elites - nowadays more than half of young adult age cohorts - than was ever the case in the past. Indeed, in most postindustrial societies opportunities for higher education have increased more rapidly than have the available positions to which this education supposedly leads. The result is that many non-manual personnel are not confident that their qualifications for the positions they hold or seek will impress and persuade remote elite decision-makers to employ, retain, or advance them. They are uncomfortably aware that a great many other persons have similar or identical qualifications.

This is the basic source of pressures to formalize decision-making processes in postindustrial work organizations. Insecure insiders are trying, quite rationally, to defend the positions they hold or seek on the basis of qualifications in which they have little confidence. Consequently, they try to impose procedural safeguards against arbitrary, and from their standpoints, uninformed decisions that affect their careers. They demand greater participation in the processes leading to these decisions, partly to present their credentials in the best possible light, and partly to prevent decisions that might go against them. Indeed, they demand the right to appeal decisions unfavorable to them. Given the large numbers of people competing for insider positions, the relative uniformity of their qualifications, and the remorseless insistence on 'merit' (in the sense of measurable indicators), it is plausible to think that the pressures to formalize decision processes will increase indefinitely in postindustrial societies. Yet beyond some point this is likely to result in paralysis and accompanying societal setbacks.

It is idle to believe that these tensions and conflicts have some simple solution. If pressures from insiders for procedural safeguards and openness in organizational decisions are to be kept to a manageable level, much respect for acquired rights and statuses will have to be given. More specifically, the price of continued elite autonomy and latitude in decision-making will be accepting the acquired rights of employees located in a work organization's more responsible and visible positions. These acquired rights include having a say in the organization's decision processes and being able to count on receiving preference over candidates from outside the organization for advancements to higher positions. Only by emphasizing such 'rights of possession' at the expense of ostensible 'meritocracy' and 'democracy' can the insecurities of insiders be abated.

In the longer run more problematic remedies might become feasible. For example, currently widespread opportunities for higher education might be reduced, or specialized and high prestige schools, akin to France's grandes 
écoles, might be superimposed on universities so that the number of persons formally qualified for middle- and higher-level organizational positions will more nearly approximate the number of positions actually available. Conceivably, the whole question of how children in affluent families grow up might be tackled. But all remedies will necessarily be compromises. Elites will lose more of their decision-making autonomy and latitude, although they may be able to retain enough to avoid organizational paralysis and its dire consequences.

\section{RELATIONS BETWEEN ELITES AND OUTSIDERS}

Outsiders are all those adults in postindustrial societies who are more or less unemployable for objective or subjective reasons, plus those who do not have accepted and honorific statuses of dependency on the working population. Instead of being relegated to beggary or starvation, most of these outsiders are reluctantly and grudgingly accorded some public support. This was especially so during the initial experience with postindustrial conditions when there rather suddenly appeared to be no serious need for additional persons in the workforce. High economic productivity, in which vast quantities of goods were being produced on the basis of ever smaller direct applications of human labor, was evident. An unprecedented quantity of manufactured goods was being turned out by 30-40 percent of the workforce, employed mainly in factories at what by historic standards were short work hours in reasonably clean and safe workplaces. Foodstuffs and other agricultural needs were being fully satisfied by farmers who made up as little as 10 and then 5 and then little more than 2 percent of the workforce. In general, the material productivity that flowed from the direct efforts of about half the workforce was more than sufficient to absorb all the monies that consumers could be induced to spend on material goods. While this created much work for specialists in advertising, there was hardly a need for many more factory workers and farmers.

The other half of a postindustrial work force - minus 10 percent initially but plus 20-25 percent after a generation or two - is employed at tasks whose products, although very important, are essentially intangible and not convincingly measurable. No one really knows with any certainty whether more of these kinds of workers are needed. For example, no one knows with any certainty if more teachers or more policemen or more accountants would actually produce more of whatever it is that teachers or policemen or accountants produce. Possibly more would produce less, but no one can really say. Much turns on the inclination of children to be taught, the disinclination 
of persons to obey laws, or the willingness of those who spend organizational or public funds to report data for accountants to analyze. Obviously, whitecollar personnel interact with each other in complicated ways, and in many situations it is simply not clear if more of them are needed to do necessary non-manual work, the definition of which is itself unclear, or if some new plan of operation might be devised to reduce the amount of work that apparently needs to be done. What is clear is that in most of these settings, as with factory workers and farmers, there is no pressing need for a great many more whitecollar personnel (Higley - Burton 1999).

These considerations mean that there is little inclination and capacity to find alternative work for persons unable or reluctant to perform whatever work is actually available. This led many in the student movements of the 1960s and 1970s to conclude that postindustrial societies are affluent and productive enough to render work strictly optional. Observing that there were enough persons working at necessary tasks to support all of the population at a high standard of living, many students inferred that if persons like themselves were not sufficiently attracted to any available work to want to pay the costs of qualifying to perform it, then let them paint pictures, sing songs, or raise babies at public expense.

Unfortunately for this easy way out, however, affluence in postindustrial societies is not the objective fact that it appeared to be when the attention of leisured young people was first drawn to it. Probably few working adults feel really affluent. Outsiders located at or beyond the fringes of the employed workforce are seriously deprived according to the prevailing standard of living. Yet there is no way in which support for them can be generally, or at least handsomely, increased without a serious sacrifice on the part of the many insiders who by no means regard themselves as affluent. This is why efforts to increase support for deprived outsiders during the 1960s and 1970s triggered taxpayer revolts and, eventually, vehement assaults on the welfare state by doctrinaire laissez-faire leaders and parties. Moreover, the possibility of improving the lot of disadvantaged outsiders through a redistribution of income is impeded by the lack of empathy between insiders who work regularly or receive fairly generous support due to their dependency statuses and outsiders who do not work regularly or do not receive much or any support as dependents. The inevitable difference of outlook between the two non-elite camps leads to the insider's question, 'Why should I sacrifice to help them?'

This means that the outsider camp cannot be made to disappear, short of drastic reductions in the sizes of postindustrial populations, such as disease pandemics or environmental disasters might cause. In the absence of such calamities, and assuming that further declines in the size of workforces relative 
to populations will occur as a result of new technological developments, such as wholesale computerization is already bringing about, the outsider camp will grow in size. What will the likely consequences be?

Probably growth of the outsider camp will threaten already fragile and tenuous mechanisms of social control in postindustrial societies. A far greater proportion of non-elites in postindustrial conditions escape the more convincing forms of social control than in past societies. Even though it is no longer strictly true, suppose that agricultural and manual industrial workers continue to produce material goods in ways that their fellow workers can directly observe, so that it is possible to tell whether a worker is loafing or not. It is, by contrast, much more difficult for most non-manual personnel to be similarly aware of whether their fellow workers are producing much or little. The policeman, for example, is present as much to discourage the commission of offenses as to arrest actual offenders. The accountant or auditor exists as much to discourage persons from misusing or embezzling funds as to detect and report the misuses and embezzlements that nonetheless occur. A manager with line authority is empowered to dismiss an employee who draws his or her pay and openly does not work. But open miscreants are few in number, and perhaps it is to personify the theoretical possibility of dismissal that is the main work such a manager performs. In short, non-manual work often has as its major purpose forestalling what might otherwise happen.

The productivity of much non-manual work is in this respect essentially un-measurable. Its productivity can only be imagined in terms of postulates about what might happen in its absence. How many children would learn arithmetic if there were no teachers regularly employed to teach them? Some certainly would. How many emotionally distraught persons would eventually work out their problems if there were no psychologists and psychiatrists and therapists to help them do so? Certainly some would. The questions that have to be asked in order to try to measure the productivity of much non-manual work are inherently without definite answers. Any answer depends on too many un-specifiable matters.

In postindustrial societies, therefore, a very large part of the workforce cannot be held to any convincing standard of work accomplishment. This is even truer, obviously, of the large body of dependents that postindustrial affluence makes possible. Almost the whole body of non-adults, a declining proportion of married women, and a large and increasing number of retired persons are in dependency statuses involving very little measurable work. If, in the extreme, all these dependents are taken together with all non-manual workers, probably three quarters of postindustrial populations, as distinct from workforces, escape the historically normal requirement to satisfy themselves 
and others that they are doing part of society's necessary work.

This is why social control mechanisms in postindustrial conditions are distinctly fragile and tenuous. It takes a great deal of political consensus, social empathy, and lack of seriously divisive grievances and discontents to keep the bulk of the population reasonably responsive to social needs. Moreover, as troubled industrial relations in all postindustrial societies indicate, it is difficult to keep the comparatively few who still perform regular, measurable, burdensome and difficult work sufficiently diligent to prevent a lapse from the high level of material productivity without which postindustrial populations in their current sizes could not exist.

It is this precarious social control that further growth of the outsider camp threatens to disrupt. For there is nothing in the circumstances of outsiders, that inclines them to respect established definitions of moderate and responsible behavior. Having no stake in the existing social structure and small chance of obtaining one, outsiders can eke out acceptable standards of living only by tactics that amount to beggary or brigandage. Their demands are essentially non-negotiable because they have little or nothing to lose by pressing them in an unrestrained manner. And in pressing such demands the most important leverage that outsiders have is the threat to disrupt in fairly horrendous ways the already precarious social controls of the society that has placed them outside. Thus, if the numbers of outsiders grow appreciably further, it is hard to see how the performance of those doing necessary tasks can be continued, unless, of course, the outsiders are greatly stigmatized and repressed by force. In this context, it is relevant to note that at present 2.25 million persons, nearly all of whom can safely be classified as outsiders, are incarcerated in 5,000 American prisons, and another 2 million are in the clutches of the American penal system so that their behavior is closely watched. It is not too much to say that continued growth of the outsider camp poses a basic threat to the maintenance of liberal and humane values in postindustrial societies.

Elites will have to devise policies that terminate the trend toward a still greater insider-outsider division among non-elites. But the room for compromise that is probably available with respect to relations between elites and insiders does not appear to be present as regards relations between insiders and outsiders and between elites and outsiders. One can only think of improbable and distinctly unsavory policies, such as using taxation and other measures to discourage procreation among more prosperous families in order to reduce the number of leisured young people who are ambivalent about pursuing adult careers that pinch their leisured activities. This might open up more work positions for disadvantaged youth and it might help restore the ambitious, upwardly mobile persons, familiar during socioeconomic development, 
to numerical prominence in postindustrial societies. But short of this most unlikely expedient, it will be necessary to make the experiences of leisured young people more relevant to the needs of adult life. Possibly this can be done, to some extent, by involving them in meaningful civic activities such as organized efforts to protect and restore parts of the despoiled environment or, of course, conscription into the military or some other public service. It may also be possible to re-define some adult statuses in areas like community recreation, entertainment, and adult education to create publicly acceptable work roles for those who lack strong career ambitions. In addition, where outsiders have been assigned their locations on the basis of identifiable group characteristics like race, ethnicity or gender, and where they can plausibly claim to have suffered discrimination as a consequence, placing some of them deliberately in prestigious occupational positions may be helpful. This kind of 'affirmative action' has been practiced with some success in the United States as regards African Americans and many women, and it is now appropriate in European societies with large Muslim and other immigrant communities. Finally, the problem of job insecurity can be reduced somewhat by defining honorific dependency statuses more broadly. Mandatory early retirement ages and elongating the time that students spend in schools and universities illustrate what might be done, though it must be admitted that under-funded pension systems and increasing costs of tertiary education are compelling later retirement ages and shorter periods of university study.

While some of these palliatives might be feasible, most of them are widely viewed as undesirable ideologically and politically. To a considerable degree, therefore, their adoption would depend upon intellectual and political innovation by elites. Not only must the problem of the relation between insiders and outsiders be more clearly recognized, a distinctly less sentimental version of liberal doctrine than that which currently has a hold on elite thinking must be adumbrated (e.g. Higley 2009). It may fairly be asked if hard-pressed elites in postindustrial societies are in a position to undertake this innovation. But even if the answer is affirmative, a doctrinal revision of liberal ideas and values will not suffice to eliminate the problems discussed here. In the last analysis, substantial net population decline in postindustrial societies may be necessary. 


\section{REFERENCES}

Bell, Daniel (1973), The coming of Post-Industrial Society, New York: Basic Books (Re-issued with a new foreword, 1999)

Borchert, Jens (2009), “They ain't making elites like they used to: the never-ending trouble with democratic elitism", Comparative Sociology Vol. 8, No. 3, pp. 345363.

Engelstad, Fredrik (2009), "Democratic elitism-conflict and consensus", Comparative Sociology Vol. 8, No. 3, pp. 383-401.

Field, G. Lowell - John Higley (1980), Elitism, London, Routledge

Higley, John (2009), "Democratic elitism and western political thought", Comparative Sociology Vol. 8, No. 3, pp. 440-458.

Higley, John - Michael Burton (1999), "Elites, mass publics, and democratic prospects In postindustrial societies", International Review of Sociology Vol. 9, No. 2, pp. 221-238.

Higley, John - Michael Burton (2006), Elite Foundations of Liberal Democracy, Lanham MD: Rowman \& Littlefield

Körösényi, András (2009), "Beyond the happy consensus about democratic elitism", Comparative Sociology Vol. 8, No. 3, pp. 364-382.

Przeworski, Adam (1999), "The minimalist conception of democracy: a defense" in: Ian Shapiro - Casiano Hacker-Cordon, eds., Democracy's Value, Cambridge, Cambridge University Press, pp. 23-55.

Schumpeter, Joseph (1942), Capitalism, Socialism, and Democracy, New York, Harper\& Row 